Section Editor Mitchell S.V. Elkind, MD, MS

Antonios Kerasnoudis, MD*

Bernhard F. Décard, MD* Ralf Gold, MD

Correspondence to

Dr. Kerasnoudis:

antonis.kerasnoudis@gmail.com

Clinical Reasoning:

\title{
A 48-year-old woman with progressive spastic-ataxic gait
}

\section{SECTION 1}

A 48-year-old woman was referred for evaluation of progressive gait ataxia and stiffness of both legs over 6 months.

She had first noticed gait disturbance while walking with her husband and she reported neither pain nor sensory deficits. She had a history of non-Hodgkin lymphoma (NHL) treated with chemotherapy and radiotherapy 20 years ago. Medical history further revealed osteoporosis and 15 pack-years of smoking.

Examination revealed sensory gait ataxia with impaired proprioception and slightly reduced vibration sense on the lower extremities (internal malleolus $5 / 8$, patella $7 / 8$ bilaterally, using a graduated Rydel-Seiffer tuning fork $[128 \mathrm{~Hz}]$ with an arbitrary scale from 0 [minimum score] to 8 [maximum score], to quantify the severity of pallhypesthesia), spastic paraparesis (4/5 for the hip flexors on the Medical Research Council scale) with brisk reflexes, and bilateral Babinski signs. The pinprick sensation was normal in all extremities and bladder function was not affected. The remainder of the general, neurologic, and mental examination was unremarkable. There was no family history of neurologic diseases and the patient did not take any medication.

\section{Question for consideration:}

1.What is your differential diagnosis at this stage? 


\section{SECTION 2}

This patient presented with a subacute onset of a spasticataxic gait with impaired proprioception of the lower limbs. The constellation of spastic paraparesis and bilateral Babinski signs suggests an upper motor neuron syndrome. The time course hints at possible etiologies: neoplastic, metabolic, inflammatory, and neurodegenerative processes typically have a subacute onset. Therefore, our differential diagnosis included chronic inflammatory and neurodegenerative diseases of the CNS (e.g., primary progressive multiple sclerosis, myelitis in the con- text of systemic inflammatory diseases like sarcoidosis or Sjögren syndrome, hereditary spastic paraplegia). CNS neoplasms, paraneoplastic syndromes, infectious diseases (e.g., human T-lymphotropic virus [HTLV], HIV, syphilis, Lyme disease), vascular malformations (e.g., arteriovenous fistula), and metabolic disorders of the CNS (e.g., vitamin $\mathrm{B}_{12}$ deficiency) were also considered.

\section{Question for consideration:}

1.What additional diagnostic tests would you consider? 


\section{SECTION 3}

To narrow down the diagnosis, blood and CSF examinations, evoked potentials, and MRI should be performed.

Laboratory tests including complete blood count, metabolic panel, electrophoresis, immunofixation, C-reactive protein, angiotensin-converting enzyme, HIV, Treponema pallidum particle agglutination assay, antinuclear antibodies, rheumatoid factor, and vitamin $\mathrm{B}_{12}$ were all within normal limits. CSF examination showed no pleocytosis but an elevated protein level of $762 \mathrm{mg} / \mathrm{L}$ (laboratory standard $<450 \mathrm{mg} / \mathrm{L})$. Glucose and lactate levels were normal and oligoclonal bands could not be detected in the CSF. CSF PCR testing was negative for herpes simplex virus 1 and 2, varicella-zoster virus, cytomegalovirus, Epstein-Barr virus, and HTLV 1 and 2. While paraneoplastic antibody screening for amphiphysin, anti-Yo, and anti-Ri was negative, anti-HuD antibodies were detected in both serum and CSF.
Motor evoked potentials (MEP) from the peroneal nerves bilaterally showed pathologic central motor conduction latencies (right $22 \mathrm{~ms}$, left $24 \mathrm{~ms}$, laboratory standard $<17 \mathrm{~ms}$ ), but normal findings from the ulnar nerves (right $8 \mathrm{~ms}$, left $7.5 \mathrm{~ms}$, laboratory standard $<9 \mathrm{~ms}$ ), suggesting a myelopathy. Somatosensory evoked potentials (SSEP) from the tibial nerves showed pathologic latencies (P40-wave latency right $50 \mathrm{~ms}$, left $55 \mathrm{~ms}$, laboratory standard $<44 \mathrm{~ms}$ ), while the SSEP from the median nerves were normal (P20-wave latency right $20 \mathrm{~ms}$, left $18 \mathrm{~ms}$, laboratory standard $<22 \mathrm{~ms}$ ). Visual evoked potentials were also normal (P100-wave latency right $115 \mathrm{~ms}$, left $114 \mathrm{~ms}$, laboratory standard $<121 \mathrm{~ms}$ ). Cranial and spinal contrastenhanced MRI revealed no inflammatory lesions, atrophy, neoplasms, or cerebrovascular diseases.

\section{Questions for consideration:}

1. What would you do next in the management of this patient?

2.What is the diagnosis? 


\section{SECTION 4}

Taking into account the patient's history of NHL and the detection of paraneoplastic anti-HuD antibodies, we performed further cancer screening. As chest and abdominal contrast-enhanced CT scans showed no signs of a neoplasm, we conducted additional ${ }^{18}$ fludeoxyglucose-PET of the whole body, which revealed hypermetabolic lesions in the left upper lung lobe and the mediastinum, suggestive of a lung carcinoma (LC) with a solitary lymph node metastasis (LM) (figure). For diagnostic confirmation and treatment, we referred the patient to a thoracic surgery department.

Histologic examination confirmed the diagnosis of small-cell LC (SCLC) with mediastinal LM (T1b, N1, M0). Subsequently the patient received 5 courses of adjuvant chemotherapy with etoposide and cisplatin.

The clinical presentation and additional findings supported the diagnosis of anti-HuD-positive paraneoplastic myelopathy (HuD-M). Following surgery and chemotherapy, the gait ataxia slightly improved over the next 6 months, but the spastic paraparesis showed no improvement.

\section{Question for consideration:}

1. What other therapy would you consider to further improve the gait disturbance due to paraneoplastic myelopathy?
Figure

${ }^{18}$ FDG-PET scans

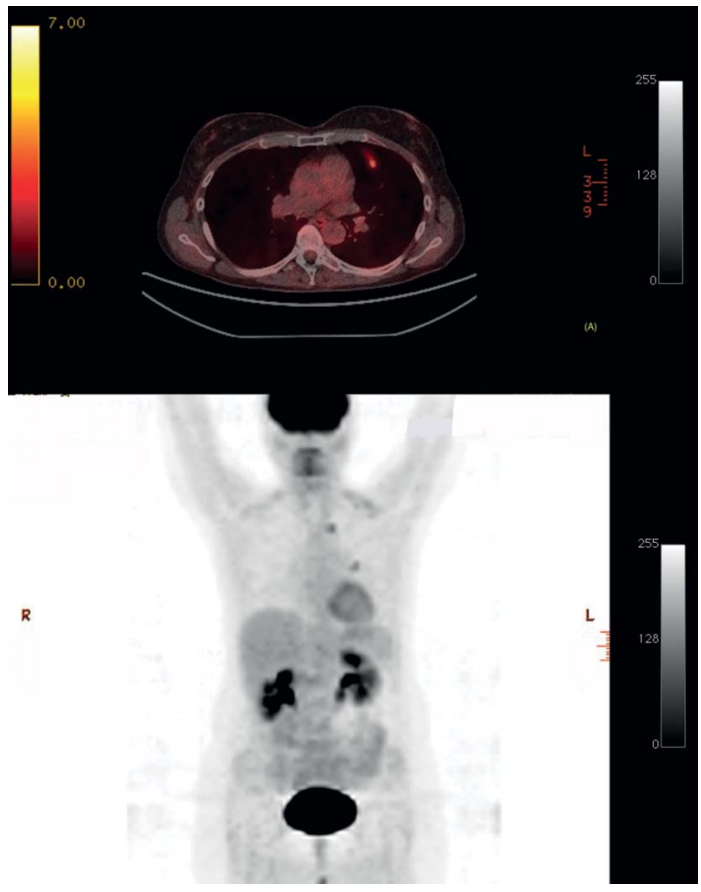

(A) ${ }^{18}$ fludeoxyglucose (FDG)-PET scan with hypermetabolic lesions in the left upper lung lobe and mediastinum, suggestive of a lung carcinoma with solitary lymph node metastasis. (B) Whole-body ${ }^{18}$ FDG-PET scan depicts the carcinoma of the left upper lung lobe and the solitary lymph node metastasis. 


\section{SECTION 5}

After administration of $500 \mathrm{mg}$ methylprednisolone IV on 5 consecutive days, only a mild improvement of the ataxia was observed. Considering the preexisting osteoporosis and the myelopathy, we decided against further systemic corticosteroids, and initiated an offlabel therapeutic approach with repeated intrathecal injections of triamcinolone. Thereafter, the patient showed a remarkable improvement of gait ataxia and spastic paraparesis as evaluated by clinical and electrophysiologic measures (MEP, SSEP).

After normal diagnostic follow-up of the SCLC for more than 2 years, we initiated immunosuppressive therapy with cyclosporine, aiming at trough levels of 70-140 ng/mL. Thereafter, the patient's neurologic condition remained stable.

DISCUSSION Paraneoplastic neurologic disorders (PNDs) include a group of heterogeneous neurologic syndromes in patients with an underlying neoplasm. Several antibodies to onconeural antigens are found in CNS paraneoplastic disorders including anti-Hu immunoglobulin G (IgG). The incidence of PNDs is $0.01 \%$ of all cancer patients. ${ }^{1}$ Their manifestation is attributed to remote immunologic effects of malignancy and is not related to direct invasion by the tumor or metastases.

In most cases, generation of anti-Hu IgG is triggered by underlying SCLC, typically limited in stage and otherwise silent. The target of the $\mathrm{Hu}$ antibodies is a family of 4 known proteins (Hel-N1, Hu, HuD, HuR). ${ }^{2}$ The $\mathrm{Hu}$ antigens have been detected both in the nucleus and the plasma membrane of SCLC and neuroblastomas. ${ }^{3}$ There is growing evidence that an immune response against these antigens might initially serve to limit the growth and spread of the neoplasm. In the further course of disease, this immune response becomes misdirected against nervous tissues (e.g., nuclei of neurons in CNS and dorsal root ganglion cells), resulting in immunologically mediated neurologic injury. ${ }^{4}$ However, as the targets of $\mathrm{HuD}$ antibodies are intracellular proteins, their pathogenic role is unclear. T-cell cytotoxicity is thought to be a more likely mechanism to explain the neuronal cell loss occurring in these serious conditions.

The clinical features of PNDs are diverse and paraneoplastic myelopathies are rare and generally unrecognized. The frequency of HuD-M ranges from $11 \%$ to 60\%..$^{5-7}$ The HuD-M typically consists of a subacute progressive loss of motor or sensory function usually accompanied by a sphincter disorder. Imaging studies may demonstrate intramedullary T2 signal change or be normal. CSF analysis usually shows increased protein levels and mild lymphocytosis, while tumor cells are lacking.

The mainstay of the treatment for HuD-M is the early identification and elimination of the underlying tumor. Complete tumor resection seems to have a favorable influence on the course of HuD-M. SCLC of patients with $\mathrm{HuD}-\mathrm{M}$ may have a slightly better prognosis than that of patients without HuD-M. A total of $70 \%$ of patients show stability of the neurologic deficits after tumor treatment and tumor complete response is the only predictive factor of $\mathrm{HuD}-\mathrm{M}$ stabilization. Immunotherapy does not modify the outcome of the tumor or the HuD-M. ${ }^{8}$

Additional immunosuppressive therapies can be considered in cases where the malignancy has not been identified, in cases where oncologic treatment has been completed, or in conjunction with cancer treatment. ${ }^{9}$ Steroids, IV immunoglobulin, plasma exchange, rituximab, and cyclophosphamide have been reported as therapies for other PNDs. ${ }^{10}$ The selection of the immunomodulatory or immunosuppressive agent for the treatment of the PND should be decided individually and based on the clinical presentation.

Although there is no consensus on standard dosages, steroids alone or in combination with other immunosuppressive agents are well-established in the treatment of PNDs. In our case, we aimed empirically at cyclosporine trough levels of 70-140 ng/mL, which are lower than the trough levels used in transplantation medicine. Taking into account this patient's history of osteoporosis and the poor clinical response after systemic application of methylprednisolone, we performed an individualized therapeutic approach with repeated intrathecal injections of triamcinolone in order to reduce systemic side effects of steroids and achieve symptomatic effects on spinal symptoms. Systematic data on intrathecal application of triamcinolone in HuD-M do not exist.

HuD-M should always be considered in the differential diagnosis of patients with subacute onset of spinal symptoms without concomitant signs of a chronic inflammatory disease. Our case highlights the importance of an exhaustive search for malignancies and comprehensive evaluation for onconeuronal antibodies. If a PND is suspected and no cancer is found initially, the clinical suspicion should remain and cancer screening needs to be repeated. As most of the patients have residual neurologic symptoms even after curative cancer therapies and controlled trials for the treatment of PND are lacking, there is a need for appropriate supportive care and symptomatic therapies. Residual neurologic symptoms of the PNDs can be ameliorated by multimodal therapy.

\section{AUTHOR CONTRIBUTIONS}

Concept and design of the article: Drs. Kerasnoudis and Décard. Acquisition of data: Drs. Kerasnoudis and Décard. Analysis and interpretation of data: Drs. Kerasnoudis, Décard, and Gold. Drafting of manuscript: Drs. Kerasnoudis and Décard. Critical revision of the manuscript: Drs. Décard and Gold. Administrative, technical, and material support: Dr. Gold. 


\section{ACKNOWLEDGMENT}

The authors thank Aiden Haghikia and Hans-Hartmut Peter for critical reading of the manuscript.

\section{STUDY FUNDING}

No targeted funding reported.

\section{DISCLOSURE}

A. Kerasnoudis reports no disclosures. B. Décard received personal compensation as a speaker for Teva. R. Gold has received consultation fees and speakers honoraria from BayerSchering, BiogenIdec, MerckSerono, Novartis, Sanofi-Aventis, and Teva, and acknowledges grant support from BayerSchering, BiogenIdec, MerckSerono, Sanofi-Aventis, and Teva, all unrelated to this manuscript. Go to Neurology.org for full disclosures.

\section{REFERENCES}

1. Dalmau J, Rosenfeld MR. Paraneoplastic syndromes of the CNS. Lancet Neurol 2008;7:327-340.

2. Manley GT, Sillevis-Smitt P, Dalmau J, Posner JB. $\mathrm{Hu}$ antigens: reactivity with $\mathrm{Hu}$ antibodies, tumor expression and major immunogenic sites. Ann Neurol 1995;38: 102-110.

3. Tora M, Graus F, de Bolos C, Real FX. Cell surface expression of paraneoplastic encephalomyelitis/sensory neuronopathy-associated $\mathrm{Hu}$ antigens in small-cell lung cancer and neuroblastomas. Neurology 1997;48:735741.

4. Rosenblum MK. Paraneoplasia and autoimmunologic injury of the nervous system: the anti-Hu syndrome. Brain Pathol 1993;3:199-212.

5. Flanagan EP, McKeon A, Lennon VA, et al. Paraneoplastic isolated myelopathy: clinical course and neuroimaging clues. Neurology 2011;76:2089-2095.

6. Graus F, Keime-Guibert F, Rene R, et al. Anti-Huassociated paraneoplastic encephalomyelitis: analysis of 200 patients. Brain 2001;124:1138-1148.

7. Sillevis Smitt P, Grefkens J, de Leeuw B, et al. Survival and outcome in 73 anti-Hu positive patients with paraneoplastic encephalomyelitis/sensory neuronopathy. J Neurol 2002;249:745-753.

8. Keime-Guibert F, Graus F, Broet P, et al. Clinical outcome of patients with anti-Hu-associated encephalomyelitis after treatment of the tumor. Neurology 1999;53: 1719-1723.

9. Sadeghian H, Vernino S. Progress in the management of paraneoplastic neurological disorders. Ther Adv Neurol Disord 2010;3:43-52.

10. Vernino S, O'Neill BP, Marks RS, O'Fallon JR, Kimmel DW. Immunomodulatory treatment trial for paraneoplastic neurological disorders. Neuro Oncol 2004;6:55-62. 


\section{Neurology}

Clinical Reasoning: A 48-year-old woman with progressive spastic-ataxic gait Antonios Kerasnoudis, Bernhard F. Décard and Ralf Gold

Neurology 2013;81;e75-e80

DOI 10.1212/WNL.0b013e3182a43ad9

This information is current as of September 9, 2013

Updated Information \& Services

References

Subspecialty Collections

Permissions \& Licensing

Reprints including high resolution figures, can be found at: http://n.neurology.org/content/81/11/e75.full

This article cites 10 articles, 3 of which you can access for free at: http://n.neurology.org/content/81/11/e75.full\#ref-list-1

This article, along with others on similar topics, appears in the following collection(s):

All Oncology

http://n.neurology.org/cgi/collection/all_oncology

Paraneoplastic syndrome

http://n.neurology.org/cgi/collection/paraneoplastic_syndrome

\section{PET}

http://n.neurology.org/cgi/collection/pet

Transverse myelitis

http://n.neurology.org/cgi/collection/transverse_myelitis

Information about reproducing this article in parts (figures,tables) or in its entirety can be found online at:

http://www.neurology.org/about/about_the_journal\#permissions

Information about ordering reprints can be found online:

http://n.neurology.org/subscribers/advertise

Neurology ${ }^{\circledR}$ is the official journal of the American Academy of Neurology. Published continuously since 1951, it is now a weekly with 48 issues per year. Copyright @ 2013 American Academy of Neurology. All rights reserved. Print ISSN: 0028-3878. Online ISSN: 1526-632X.

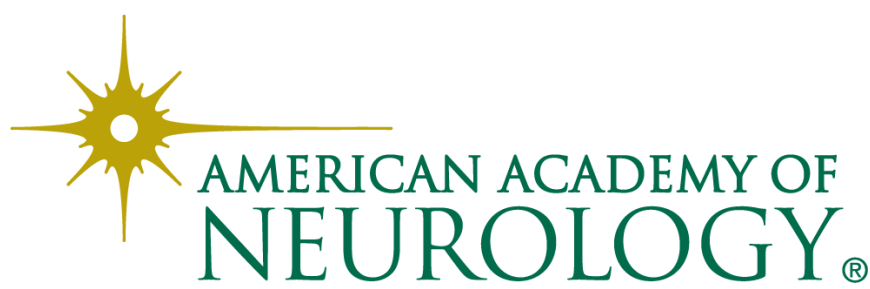

